\title{
Natural Products for Chemoprevention of Breast Cancer
}

\author{
Eun-Yi Ko, Aree Moon \\ College of Pharmacy, Duksung Women's University, Seoul, Korea
}

\begin{abstract}
Breast cancer is the primary cause of cancer death in women. Although current therapies have shown some promise against breast cancer, there is still no effective cure for the majority of patients in the advanced stages of breast cancer. Development of effective agents to slow, reduce, or reverse the incidence of breast cancer in high-risk women is necessary. Chemoprevention of breast cancer by natural products is advantageous, as these compounds have few side effects and low toxicity compared to synthetic compounds. In the present review, we summarize natural products which exert chemopreventive activities against breast cancer, such as curcumin, sauchinone, lycopene, denbinobin, genipin, capsaicin, and ursolic acid. This review examines the current knowledge about natural compounds and their mechanisms that underlie breast cancer chemopreventive activity both in vitro and in vivo. The present review may provide information on the use of these compounds for the prevention of breast cancer.
\end{abstract}

(J Cancer Prev 2015;20:223-231)

Key Words: Breast neoplasm, Chemoprevention, Curcumin, Sauchinone, Lycopene

\section{INTRODUCTION}

Breast cancer represents an important public health problem worldwide and is the primary cause of cancer death in women. ${ }^{1}$ Early diagnosis has become possible due to improved detection techniques. However, the mortality of patients suffering from breast cancer has increased. Current treatments including surgery, radiotherapy, adjuvant chemotherapy, and/or hormone therapies are useful for treating breast cancer, but there is still no effective cure for most patients suffering from advanced breast cancer. Recent studies have identified new pathways, biomarkers, and agents that are likely to be effective in breast cancer. ${ }^{2}$ There is an unmet need for agents that can be used to reduce the incidence of breast cancer in high-risk women. Therefore, the search for novel preventive approaches is necessary. One such approach is chemoprevention.

Cancer chemoprevention is defined as the use of natural or synthetic compounds to prevent, slow, suppress, or reverse the carcinogenic processes. Given that treatment options for patients with advanced breast cancer are limited, chemoprevention may be a rational and an appealing strategy. The discovery of novel natural drugs is important for reduction of side-effects, high selectivity, low toxicity, and better killing of cancer cells. ${ }^{3}$

The present review summarizes the current understanding of natural products which exert chemopreventive activities against breast cancer. We summarize studies on the effects of curcumin, sauchinone, lycopene, denbinobin, genipin, capsaicin, and ursolic acid against breast cancer. The structure of these natural products are shown in Figure 1. These natural compounds possess anti-inflammatory, ${ }^{4}$ anti-metastatic, ${ }^{5}$ anti-proliferative, ${ }^{6}$ anti-angiogenic, ${ }^{7}$ and anti-cancer properties in breast cancer. We focus on the possible mechanisms that may underlie the anti-cancer activities of these compounds on breast cancer progression.

Received November 14, 2015, Revised November 26, 2015, Accepted November 30, 2015

Correspondence to: Aree Moon

College of Pharmacy, Duksung Women's University, 33 Samyang-ro 144-gil, Dobong-gu, Seoul 01369, Korea

Tel: +82-2-901-8394, Fax: +82-2-901-8386, E-mail: armoon@duksung.ac.kr

Copyright (c) 2015 Korean Society of Cancer Prevention

(c) This is an Open Access article distributed under the terms of the Creative Commons Attribution Non-Commercial License (http://creativecommons.org/licenses/by-nc/4.0) which permits unrestricted non-commercial use, distribution, and reproduction in any medium, provided the original work is properly cited. 
A<smiles>COc1cc(CCC(=O)CC(=O)CCc2ccc(O)c(OC)c2)ccc1O</smiles>

B<smiles>COc1cc(CNC(=O)CC(=O)CC/C=C/C(C)C)ccc1O</smiles>

\section{C}<smiles>C/C=C(\C)CCC/C(C)=C/C=C/C(C)=C/C=C/C(C)=C/C=C/C(C)=C/C=C/C(C)=C/C=C/C(C)=C/C=C\C=C(C)C</smiles>

D<smiles>CC1CC2C(=O)C=C3OCOC34COc3cc5c(cc3C2(CC1C)C4)OCO5</smiles>

E<smiles>COC(=O)[C@H]1CO[C@H](O)[C@H]2C(CO)=CC[C@H]12</smiles>

F<smiles>COC1=CC(=O)c2ccc3cc(OC)cc(O)c3c2C1=O</smiles>

G

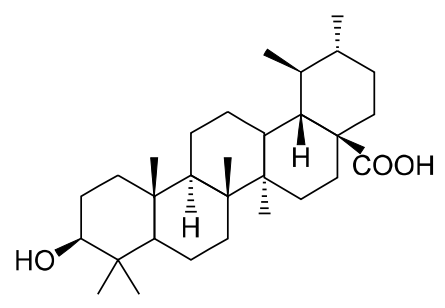

Figure 1. Chemical structures of natural products: (A) Curcumin; (B) Capsaicin; (C) Lycopene; (D) Sauchinone; (E) Genipin; (F) Denbinobin; and $(G)$ Ursolic acid.

\section{CURCUMIN}

Curcumin [1,7-bis(4-hydroxy-3-methoxyphenyl) 1,6-hepta-diene3.5-dione] is a natural dietary pigment from the root of the plant turmeric (Curcuma Ionga Linn). ${ }^{8}$ Curcumin possesses antiinflammatory, ${ }^{4}$ anti-carcinogenic, and anti-metastatic ${ }^{5}$ properties, and inhibits tumor formation. ${ }^{89}$ Curcumin significantly inhibited cancer growth and is considered a cancer chemopreventive and chemotherapeutic agent. ${ }^{10}$ Curcumin exerted in vitro anti-breast cancer activities through regulation of matrix metalloproteinase (MMP)-2, B-cell lymphoma 2 (Bcl-2), Bax, flap endonuclease 1 (Fen1), NF-E2-related factor 2 (Nrf-2) factors, and phosphoinositide 3-kinase (PI3K)/protein kinase B (Akt) signaling. ${ }^{11,12}$

There have been several studies on the chemotherapeutic effects of curcumin in breast cancer. Curcumin down-regulates MMP-2 in a dose- and time-dependent fashion and inhibits the H-Ras-induced invasive phenotype in MCF10A human breast epithelial cells (H-Ras MCF10A). ${ }^{8}$

Curcumin has a cytotoxic effect on H-Ras MCF10A cells. ${ }^{8}$ Curcumin-induced cell death involves downregulation of Bcl-2 and upregulation of Bax, two key apoptosis-linked gene products, during apoptosis in H-Ras MCF10A cells. ${ }^{8,13}$ This has also been observed in other human breast cancer cell lines such as MDA-MB-231 and MCF-7 cells. ${ }^{3,11}$ Curcumin triggers apoptosis through the PI3K/Akt signaling pathway. ${ }^{12}$ Curcumin induces Akt phosphorylation, but combination therapy with PI3K inhibitor, LY290042, synergizes the apoptotic effect. ${ }^{12}$ Blocking the PI3K/Akt survival pathway with LY290042 affects curcumin-induced apoptosis in MCF-7 cells. ${ }^{12}$

Overexpression of Fen1, which is a DNA repair-specific nuclease, is involved in the development of breast cancer, and therefore, Fen1 can be a therapeutic target in breast cancer. ${ }^{14}$ Nrf-2 is a transcription factor which regulates cellular antioxidant defense systems. ${ }^{15}$ Curcumin decreases Fen 1 promoter activity and protein expression in a dose-dependent manner and induces the expression of Nrf- 2 in breast cancer. ${ }^{15}$ The Nrf-2-dependent downregulation of Fen 1 by curcumin inhibits the proliferation of breast cancer cells. ${ }^{15}$

Bisphenol A (BPA) affects the development of estrogenresponsive breast cancer through the proliferation of estrogen receptor (ER)-positive human breast cancer cells. ${ }^{16}$ Curcumin inhibits the proliferative effects of BPA on human breast cancer cells. ${ }^{16}$ Curcumin inhibits miR-19 which is involved in BPAmediated MCF-7 cell proliferation. ${ }^{17}$ Thus, treatment with curcumin, a miR-19 inhibitor, leads to suppression of prolifera- 
tion, growth, and invasion/metastasis of cancer cells. ${ }^{17}$

The F-box protein S-phase kinase-associated protein 2 (Skp2) is involved in breast cancer progression, especially in ER/HER2 negative breast cancers. ${ }^{18}$ Curcumin inhibits cell growth by inhibition of Skp2 and induction of p27 in MDA-MB-231 human breast cancer cells. ${ }^{18}$ Taken together, curcumin inhibits cancer cell growth, especially in ER/HER2 negative breast cancers. ${ }^{18}$

\section{SAUCHINONE}

Saururus chinensis (SC) possesses anti-tumorigenic activity in MCF-7 human breast cancer cells. ${ }^{19}$ SC suppresses angiogenetic, proliferative, and anti-apoptotic activity by reducing VEGF, cyclin $\mathrm{D} 1$, and Bcl-2 gene products. ${ }^{19} \mathrm{SC}$ activates caspase-3, which plays a role in SC-induced apoptosis and can be used as a chemotherapy agent in human breast cancer cells. ${ }^{19}$ Sauchinone, a major active constituent of SC, is extracted from the root of SC. ${ }^{20}$

Sauchinone possesses anti-pyretic, diuretic, and antiinflammatory properties. ${ }^{20}$ Sauchinone has been used for the treatment of jaundice, edema, fever, and inflammatory diseases in Korean folk medicine for centuries. ${ }^{20}$ Sauchinone has been reported to inhibit bone destruction and to decrease mortality rates. $^{21}$ It exerts anti-cancer effects through control of VEGF, cyclin D1, Bcl-2, caspase-3, and the extracellular signal-regulated kinase (ERK) signaling pathway in breast cancer cells. ${ }^{19,21}$ NF-KB activity through the ERK signaling pathway leads to increased proliferation of cells and tumor growth through the transcription of anti-apoptotic proteins. ${ }^{21-23}$ Sauchinone has been used as an anti-inflammatory herbal agent that TNF- $\alpha$ expression, the ERK pathway, and NF-KB activation. ${ }^{21,24}$

\section{LYCOPENE}

Lycopene is the major carotenoid in fruits and vegetables including tomatoes. Lycopene is the most effective oxygen radical quenching agent among the carotenoids. ${ }^{25.26}$ It inhibits the growth of various human cancers including breast, ${ }^{27}$ prostate, ${ }^{28,29}$ endometrial, ${ }^{26}$ colorectal, $^{30}$ and lung cancer. ${ }^{31}$ The anticancer activities of lycopene progress through regulation of growth factor signaling, apoptosis induction, ${ }^{32}$ and changes in phase II detoxifying/antioxidant enzymes. ${ }^{31}$ In addition, lycopene inhibits tumor cell invasion, metastasis, and angiogenesis, thereby suppressing the development and growth of cancers. ${ }^{32}$ These anti-cancer activities also reduce DNA damage due to reactive oxygen species. ${ }^{33}$ Lycopene correlates with the ERKs and Akt/ mTOR signaling pathways in breast cancer. ${ }^{27,34}$
Lycopene inhibited invasion, metastasis, and proliferation of aggressive breast cancer cell lines such as H-Ras-transformed MCF10A human breast cells and MDA-MB-231 human breast cancer cells. ${ }^{27}$ Activation of ERKs and Akt was inhibited by lycopene. ${ }^{27}$ Lycopene exerts anti-proliferation, anti-invasion, and anti-migration effects through the ERKs and Akt signaling pathways in breast cancer. ${ }^{27}$ Lycopene upregulates the expression of the Bax and increases caspase-9-induced apoptosis in MCF-7 human breast cancer cells. ${ }^{34,35}$

Lycopene possesses anti-proliferative properties in triplenegative breast cancer, which is negative for expression of ER, progesterone receptor, and HER2 proteins. Lycopene induces apoptosis through Bax protein by inhibiting phosphorylation of Akt, which plays a role in apoptosis and cell survival and is downstream of mTOR. Thus, lycopene induces apoptosis by blocking the Akt/mTOR signaling pathway in triple-negative breast cancer. $^{36}$

Lycopene inhibits cell proliferation by decreasing cell viability and arresting the cell cycle in different phases. ${ }^{37,38}$ Lycopene suppresses cancer cell growth by down-regulating Skp2, which plays a role in breast cancer progression, especially in ER/HER2negative breast cancers. ${ }^{18}$ Cyclin D1 is over-expressed in breast cancer during the G1 phase. Lycopene inhibits insulin like growth factor (IGF)-1-induced cell cycle progression from $\mathrm{G} 1$ to $\mathrm{S}$ phase and reduces cyclin D1 levels, suppressing the growth of MCF-7 cells. $^{39}$

\section{GENIPIN}

Genipin is a natural product of Gardenia jasminoides Ellis and is used in the treatment of several cancers due to its anti-tumor activity. ${ }^{6}$ Genipin possesses anti-inflammatory, ${ }^{40}$ anti-angiogenic, ${ }^{7}$ anti-oxidative, $^{41}$ anti-proliferative, ${ }^{6}$ and apoptosis-inducing ${ }^{42}$ properties in cell lines. It can prevent a variety of cancers including breast, periodontal, ${ }^{40}$ gastric, lung, and liver cancer. In breast cancer, genipin regulates Bcl-2, Bax, caspase-3, JNK, p38MAPK, and reactive oxygen species (ROS) production. ${ }^{6,43}$

Genipin has anti-proliferative activity in MDA-MB-231 breast cancer cells. ${ }^{6}$ Genipin induces apoptosis in MDA-MB-231 cells by downregulating Bcl-2 and upregulating Bax and caspase-3, as well as the pro-apoptosis products JNK and p38 MAPK, inducing apoptosis and inhibiting invasion/metastasis. ${ }^{6}$ Genipin was shown to be a chemopreventive agent for preventing metastatic breast cancer. $^{6}$

Mitochondrial uncoupling protein (UCP2), which promotes tumorigenic properties, is over-expressed in MCF7 human breast 
cancer cells. ${ }^{44} \mathrm{UCP2}$ is also associated with cell viability through regulation of ROS production, apoptosis, and autophagy. ${ }^{43}$ Inhibition of UCP2 involves an increase in ROS production, apoptosis, and autophagy, and a decrease in cell viability. ${ }^{43}$ Thus, genipin decreases cancer cell viability by inhibiting UCP2. ${ }^{43}$

\section{DENBINOBIN}

Denbinobin (5-hydroxy-3,7-dimethoxy- 1,4-phenanthraquinone) is a substance extracted from Ephemerantha lonchophylla. It is isolated from the stems of Dendrobium moniliforme (Shi-Hu in Chinese medicine). ${ }^{45.46}$ Denbinobin possesses anti-cancer, anti-inflammatory, ${ }^{47}$ anti-angiogenesis, ${ }^{48}$ and apoptosis-inducing ${ }^{49}$ properties in several types of cancer cells. These effects are particularly relevant to Src kinase, NF-KB, and IGF-1 receptor (IGF-1R) in breast cancer. ${ }^{45,47}$

Src kinase activity is increased in breast cancer, is associated with aggressive disease, and can indicate poor prognosis. ${ }^{46}$ Denbinobin suppresses metastasis by suppressing Src kinase activity in human breast cancer cells. ${ }^{46}$ Denbinobin also inhibits breast cancer metastasis by regulating Src-mediated signaling pathways and can be therapeutic factor in breast cancer treatment. ${ }^{45}$

NO synthase (iNOS) and COX-2 play important roles in various inflammatory diseases. ${ }^{47}$ Denbinobin decreases iNOS and COX-2 activity in a concentration-dependent manner by inhibiting NF- $\mathrm{KB}$ activation. ${ }^{47}$ Denbinobin possesses anti-inflammatory properties and can serve as a therapeutic agent in inflammatory disease. $^{47}$

Anti-angiogenic and tumor inhibition activity are associated with the enhanced activity of IGF-1R. ${ }^{48}$ IGF-1R signaling leads to apoptosis and cell proliferation, which supports breast cancer development. ${ }^{50.51}$ Denbinobin prevents the activation of IGF-1R and its down-stream signaling pathway, thus inhibiting angiogenesis. ${ }^{48}$

\section{CAPSAICIN}

Capsaicin (trans-8-methyl-N-vanillyl-6-nonenamide) is a natural pungent ingredient found in red pepper that has anticarcinogenic, antimutagenic, and chemopreventive ${ }^{52.53}$ in a variety of cancers by inducing apoptosis. ${ }^{5457}$ It serves as an antimetastatic ${ }^{58}$ and anti-angiogenic factor. ${ }^{59}$ In breast cancer, ROS, Rac1, caspase-3, and the epidermal growth factor receptor (EGFR)/ HER-2 signaling pathway are involved in these effects. ${ }^{52,60,61}$

Capsaicin is a pro-apoptotic agent. Capsaicin is more effective for apoptosis in the presence of $\mathrm{p} 53 .^{56}$ In breast cancer, capsaicin-induced apoptosis is induced by ROS and Rac1 in H-Ras MCF10A cells. ${ }^{52}$ It is selectively induced by c-Jun N-terminal protein kinase -1 and p38, but not by ERKs. ${ }^{53}$ Capsaicin promoted concentration-dependent apoptosis in MCF-7 breast cancer cells. ${ }^{62}$ In addition, capsaicin decreased breast cancer stem cells in the MCF-7 cell line. ${ }^{62}$ Capsaicin also suppresses translocation of notch intracellular membrane domain to the nucleus. ${ }^{62}$ Capsaicin promotes apoptosis of breast cancer stem cells in MCF-7 cells by controlling Notch signaling. ${ }^{62}$

Capsaicin-induced apoptosis includes caspase-3, a pro-apoptotic factor expressed in MCF-7 cells. ${ }^{60}$ Caspase-3 also affects cell cycle arrest in the $\mathrm{S}$ phase, thereby inhibiting growth of human breast cancer cells. ${ }^{60}$ Capsaicin suppresses breast cancer cell migration and reduces the size of MDA-MB 231 breast cancer cells. ${ }^{61}$ It is associated with factors in the EGFR/HER-2 pathway, which leads to progressive tumor growth and invasion, including ERK, cyclin D1, and p27(KIP1). ${ }^{63,64}$ Capsaicin exerts anti-proliferative effects by modulating the EGFR/HER-2 pathway. ${ }^{61}$

There have been a debate regarding the anticarcinogenic and procarcinogenic effects of capsaicin. Several studies have reported that this phytochemical exerted the procarcinogenic property, particularly in skin cancer. ${ }^{65,66}$ Capsaicin act as a carcinogen or a cocarcinogen through Erk, p38, and EGFR dependent mechanisms in 12-O-tetradecanoylphorbol-13-acetate-induced skin carcinogenesis. ${ }^{65.66}$ Therefore, a cautious consideration would be required for using capsaicin as a chemopreventive agent. ${ }^{65,66}$

\section{URSOLIC ACID}

Ursolic acid (UA) is a pentacyclic triterpenoid compound extracted naturally from herbs. ${ }^{67}$ It possesses anti-cancer, anti-invasive, ${ }^{68}$ anti-metastatic, ${ }^{69}$ anti-proliferation, ${ }^{70,71}$ and antiangiogenesis $^{72}$ properties in various human cancers, and also promotes apoptosis. In addition, UA prevents the development of nonalcoholic fatty liver disease. ${ }^{67}$ Recently, ursolic acid derivatives were newly synthesized through a more efficient reaction; ${ }^{73}$ however, we have chosen to summarize only data from the natural compound here. In breast cancer, UA affects cyclin D1, CDK4, forkhead box M1 (FoxM1), Bax, Bcl-2, and MMP-2 factors and it can be used as a cancer prevention agent. ${ }^{74-77}$

UA possesses anti-cancer effects in human breast cancer cells. ${ }^{75}$ UA is related to various apoptotic factors and signaling pathways. ${ }^{75} \mathrm{UA}$ induces apoptosis and inhibits cell proliferation. ${ }^{74,75}$ CyclinD1/CDK4 correlates with cell cycle progression and cancer progression ${ }^{74}$ and FoxM1, a transcription factor, is a key for cell proliferation and cell cycle progression. ${ }^{75}$ UA-induced 
apoptosis decreases cyclinD1/CDK4 expression through regulation of FoxM1 in MCF-7 human breast cancer cells. ${ }^{75}$

UA up-regulates Bax, which is a pro-apoptosis factor, and down-regulates Bcl-2, which is an anti-apoptosis factor, leading to induction of apoptosis. ${ }^{78}$ UA-induced apoptosis involves release of cytochrome $c$ in the mitochondrial death pathway. ${ }^{77}$ UA has inhibitory effects on migration and invasion in the metastatic breast cancer cell line MDA-MB 231. ${ }^{76}$ UA reduces MMP-2 and urokinase-type plasminogen activator expression by inhibiting
NF-אB and Jun N-terminal kinase. ${ }^{76}$ UA can be a chemopreventive agent for metastatic breast cancer.

\section{OTHERS}

Terpenoids include ursolic acid, lycopene, and other polyterpenes. These terpenoids are extracted from plants or animals and are often related to chemoprevention and treatment of breast cancer. ${ }^{79}$ Triterpenoids in particular are involved in anti-

Table 1. Effects of natural products for chemoprevention of breast cancer

\begin{tabular}{|c|c|c|c|}
\hline Natural product & Mechanism & Related factor & Reference \\
\hline \multirow[t]{3}{*}{ Capsaicin } & Apoptosis & ROS, Rac1, c-Jun, JNK-1, p38, caspase-3 & $52,53,60$ \\
\hline & Cell cycle transition & & \\
\hline & Anti-proliferation & EGFR/HER2 signaling pathway & 63,64 \\
\hline Chalcone & Apoptosis, anti-angiogenesis & VEGF/VEGFR-2 signaling pathway & 61 \\
\hline Codonolactone & Anti-invasion, anti-metastasis & Runx2, MMPs & 87 \\
\hline \multirow[t]{4}{*}{ Curcumin } & Apoptosis & MMP-2, Bcl-2, Bax & $8,11,12,14$ \\
\hline & & PI3K/Akt signaling pathway & \\
\hline & Anti-proliferation & Fen1, Nrf-2, BPA proliferation, Skp2, p27 & $13,15,16,18$ \\
\hline & Cell cycle transition & miR-19 & 17 \\
\hline \multirow[t]{3}{*}{ Denbinobin } & Anti-metastasis & Src kinase & 46 \\
\hline & Anti-inflammation & NF- $\kappa B$, iNOS, COX-2 & 47 \\
\hline & Anti-angiogenesis & IGF-1R & 48 \\
\hline \multirow[t]{3}{*}{ Fangchinoline } & Apoptosis & Bax, Bcl-2, caspase-3, cytochrome $c$ & 85 \\
\hline & Anti-proliferation & Akt/GSK-3beta/cyclin D1 signaling & 85 \\
\hline & Cell cycle transition & PCNA, cyclin D1 & 85 \\
\hline Furanodiene & $\begin{array}{l}\text { Cell cycle transition, anti-invasion, } \\
\text { anti-metastasis }\end{array}$ & MMP-9 & 82,83 \\
\hline Genipin & Apoptosis & Bcl-2, Bax, caspase-3, JNK, p38MAPK, UCP2, ROS & 6,43 \\
\hline Ginsenoside & Apoptosis, cell cycle transition & MDM2 & 80 \\
\hline \multirow[t]{4}{*}{ Lycopene } & Anti-proliferation, & Skp2 & 18 \\
\hline & Anti-metastasis, anti-invasion & ERK/Akt signaling pathway & \\
\hline & Apoptosis & $\begin{array}{l}\text { Bax, caspase-9, cyclin D1 } \\
\text { Akt/mTOR sionaling pathway }\end{array}$ & 35,37 \\
\hline & Cell cycle transition & IGF-1 & 38 \\
\hline Morin & Anti-invasion, anti-metastasis & Akt pathway signaling & 86 \\
\hline Nexrutine & Apoptosis, cell cycle transition & Cyclin D1, cdk2 & 87 \\
\hline Phytoestrogens & Apoptosis, anti-angiogenesis, & ROS/p38 MAPK pathway, Bcl-2, promoters I.3/II & 93. 94 \\
\hline Psoralen & Anti-metastasis & & \\
\hline Pterostilbene & Apoptosis, anti-proliferation & Bax & 97 \\
\hline Retinoid & Apoptosis, anti-proliferation & ER/HER2 signaling & 92 \\
\hline \multirow[t]{2}{*}{ Sauchinone } & Apoptosis & VEGF, cyclin D1, Bcl-2, caspase-3 & 19 \\
\hline & Anti-inflammation & $\begin{array}{l}\text { TNF- } \alpha, \text { NF- } \kappa B \\
\text { ERK signaling pathway }\end{array}$ & 21,24 \\
\hline Tehranolide & Anti-proliferation, cell cycle transition & $\begin{array}{l}\text { PI3K/Akt/cyclin D1 pathway, ROS, cytochrome } c \text {, } \\
\text { Bax, Bcl-2 }\end{array}$ & 98 \\
\hline \multirow[t]{2}{*}{ Ursolic acid } & Apoptosis & $\begin{array}{l}\text { FoxM1, cyclin D1/CDK4 } \\
\text { Bax, Bcl-2, cytochrome } c\end{array}$ & $75,77,78$ \\
\hline & Anti-metastasis & NF-кB, JNK, MMP2, u-PA & 76 \\
\hline
\end{tabular}

ROS, reactive oxygen species; JNK, Jun N-terminal protein kinase; MMP, matrix metalloproteinas; Bcl-2, B-cell lymphoma 2; PI3K, phosphoinositide 3-kinase; Akt, protein kinase B; Fen1, flap endonuclease 1; Nrf-2, NF-E2-related factor 2; BPA, bisphenol A; Skp2, S-phase kinase-associated protein 2; iNOS, NO synthase; IGF-1R, insulin like growth factor 1 receptor; PCNA, proliferating cell nuclear antigen; UCP2, uncoupling protein; MDM2, mouse double minute 2; ERK, extracellular signal-regulated kinase; IGF, insulin like growth factor; ER, estrogen receptor; FoxM1, forkhead box M1; u-PA, urokinase-type plasminogen activator. 
inflammation, cell cycle regulation, proliferation, and apoptosis through control of multiple signal transduction pathways. ${ }^{79}$

Ginsenoside 25-OCH3-PPD, a natural product, inhibits breast cancer growth and metastasis by down-regulating the mouse double minute 2, playing role in cancer development and growth, and decreases cancer cell survival through induction of apoptosis and cell cycle transition to G1 phase. ${ }^{80.81}$ Furanodiene extracted from Curcuma wenyujin inhibits breast cancer proliferation and growth by inducing cell cycle arrest at the G0/G1 phase and suppressing tumor growth. ${ }^{82}$ Furanodiene suppresses adhesion, migration, and invasion in metastatic breast cancer cells by modulating MMP-9. Furanodiene, however, does not induce apoptosis. ${ }^{83}$ Codonolactone isolated from Chloranthus henryi Hemsl inhibits breast cancer cell migration, invasion, and metastasis through downregulation of Runx2 transcriptional activity and inhibition of MMPs. ${ }^{84}$

Fangchinoline induces apoptosis through Bax, Bcl-2, caspase-3, and cytochrome $c$ and inhibits proliferation via Akt/GSK-3beta/ cyclin D1 signaling in breast cancer cell line. ${ }^{85}$ Fangchinoline is involved in the cell cycle transition to G1 phase through proliferating cell nuclear antigen and cyclin D $1 .{ }^{85} \mathrm{~A}$ flavonoid morin from Moraceae possesses anti-oxidant, anti-inflammatory, and anti-carcinogenic properties, and suppresses invasion and metastasis in the breast cancer cell line MDA-MB-231 through inhibition of the Akt pathway. ${ }^{86}$

The herbal extract Nexrutine from the plant Phellodendron amurense possesses anti-cancer effects on ER-negative breast cancer. Nexrutine is associated with apoptosis and cell cycle transition to G1 phase through protein expression of Cyclin D1 and cdk2. ${ }^{87}$ Psoralen isolated from the seeds of Psoralea corylifolia $L$. inhibits metastasis to bone in breast cancer. ${ }^{88}$ Retinoid inhibits growth of breast cancer cells by signaling on ER and HER2 2.89 Retinoid possesses anti-proliferative and apoptotic effects in breast cancer. ${ }^{90}$

Phytoestrogens such as resveratrol, daidzein, quercetin, and genistein can affect cell signaling pathways related to proliferation, apoptosis, and inflammation. ${ }^{91}$ They possess anti-oxidant, anti-proliferative, anti-angiogenic, anti-apoptotic, and anti-cancer properties in breast cancer. ${ }^{92}$ Another dietary phytoestrogen, arctigenin, induces apoptosis in ER-negative breast cancer via the ROS/p38 MAPK pathway and regulation of Bcl-2. ${ }^{93}$ Genistein and resveratrol are able to suppress promoters I.3/II, which are the major promoters for aromatase expression; aromatase expression can lead to overproduction of estrogen, promoting breast cancer. ${ }^{94}$ In addition, resveratrol dose-dependently inhibits the growth of estrogen receptor-positive human breast cancer cells. ${ }^{95}$
A dietary chalcone-type flavonoid isoliquiritigenin (ISL) inhibits neoangiogenesis through the VEGF/VEGFR-2 signaling pathway in breast cancer. ISL suppresses VEGF/VEGFR-2 signaling and elevates apoptosis. ${ }^{96}$ A natural compound pterostilbene possesses anti-proliferative effects and induces apoptosis through Bax activation. ${ }^{97}$ Tehranolide, isolated from Artemisia diffusa, inhibits proliferation and growth of human breast cancer cells by inducing GO/G1 arrest. It is associated with the PI3K/Akt/cyclin D1 pathway and regulation of ROS, cytochrome $c$, Bax and Bcl-2 in breast cancer cells. ${ }^{98}$

\section{CONCLUSIONS}

This article provides information on selected natural products for chemoprevention against breast cancer. Most of these natural products involve apoptotic factors, including Bcl-2 and Bax. Many natural products affect signaling pathways such as ERKs, Akt/mTOR, and EGFR/HER2. Some of these compounds show inhibitory effects on tumor growth, angiogenesis, proliferation, invasion, and metastasis. We summarized the mechanistic basis of chemoprevention with compounds in a Table 1 and a Figure 2. These natural products can be preventive agents that can reduce side effects and improve the effect of drugs on human breast cancer, while maintaining high selectivity and low toxicity. The identification of natural products that can control or inhibit potential molecular targets will provide many opportunities for

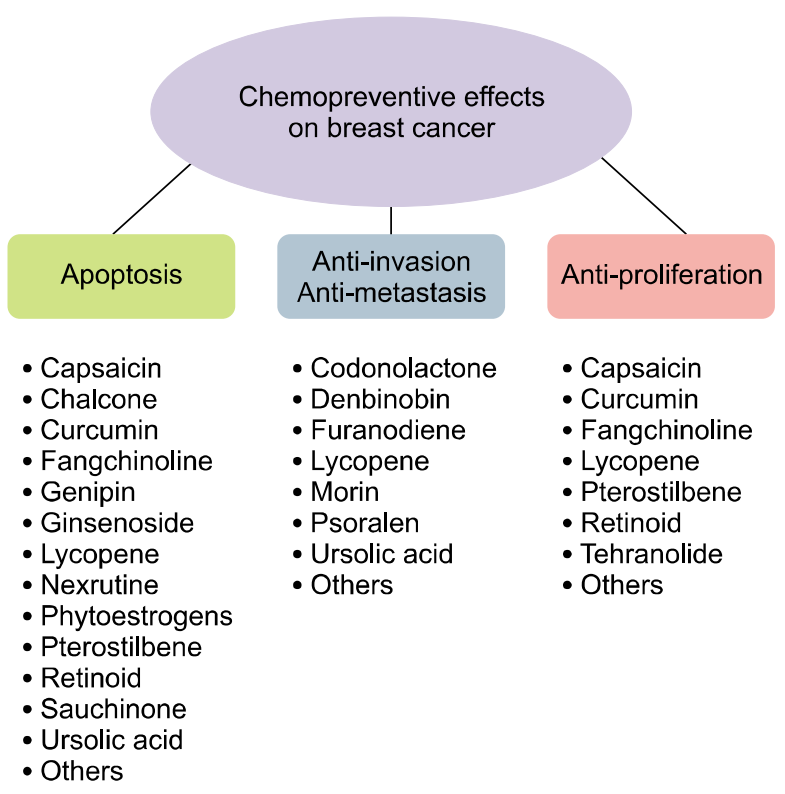

Figure 2. Chemopreventive effects of natural compounds on breast cancer. 
chemoprevention.

\section{ACKNOWLEDGMENTS}

The present study was supported by the Duksung Women's University Research Grant 2014.

\section{CONFLICTS OF INTEREST}

No potential conflicts of interest were disclosed.

\section{REFERENCES}

1. Jemal A, Bray F, Center MM, Ferlay J, Ward E, Forman D. Global cancer statistics. CA Cancer J Clin 2011;61:69-90.

2. Cazzaniga $\mathrm{M}$, Bonanni B. Breast cancer chemoprevention: old and new approaches. J Biomed Biotechnol 2012;2012:985620.

3. Khazaei Koohpar Z, Entezari M, Movafagh A, Hashemi M. Anticancer activity of curcumin on human breast adenocarcinoma: role of Mcl-1 gene. Iran J Cancer Prev 2015;8:e2331.

4. Conney AH, Lysz T, Ferraro T, Abidi TF, Manchand PS, Laskin JD, et al. Inhibitory effect of curcumin and some related dietary compounds on tumor promotion and arachidonic acid metabolism in mouse skin. Adv Enzyme Regul 1991:31:385-96.

5. Menon LG, Kuttan R, Kuttan G. Anti-metastatic activity of curcumin and catechin. Cancer Lett 1999;141:159-65.

6. Kim ES, Jeong CS, Moon A. Genipin, a constituent of Gardenia jasminoides Ellis, induces apoptosis and inhibits invasion in MDA-MB-231 breast cancer cells. Oncol Rep 2012;27:567-72.

7. Park EH, Joo MH, Kim SH, Lim CJ. Antiangiogenic activity of Gardenia jasminoides fruit. Phytother Res 2003:17:961-2.

8. Kim MS, Kang HJ, Moon A. Inhibition of invasion and induction of apoptosis by curcumin in H-ras-transformed MCF10A human breast epithelial cells. Arch Pharm Res 2001;24:349-54.

9. Rao CV, Rivenson A, Simi B, Reddy BS. Chemoprevention of colon carcinogenesis by dietary curcumin, a naturally occurring plant phenolic compound. Cancer Res 1995:55:259-66.

10. Jiao Y, Wilkinson J 4th, Di X, Wang W, Hatcher H, Kock ND, et al. Curcumin, a cancer chemopreventive and chemotherapeutic agent, is a biologically active iron chelator. Blood 2009;113:462-9.

11. Lv ZD, Liu XP, Zhao WJ, Dong Q, Li FN, Wang HB, et al. Curcumin induces apoptosis in breast cancer cells and inhibits tumor growth in vitro and in vivo. Int J Clin Exp Pathol 2014;7:2818-24.

12. Kizhakkayil J, Thayyullathil F, Chathoth S, Hago A, Patel M, Galadari S. Modulation of curcumin-induced Akt phosphorylation and apoptosis by PI3K inhibitor in MCF-7 cells. Biochem Biophys Res Commun 2010;394:476-81.

13. Lowe SW, Lin AW. Apoptosis in cancer. Carcinogenesis 2000;21: 485-95.

14. Singh P, Yang M, Dai H, Yu D, Huang Q, Tan W, et al. Overexpression and hypomethylation of flap endonuclease 1 gene in breast and other cancers. Mol Cancer Res 2008;6:1710-7.

15. Chen B, Zhang Y, Wang Y, Rao J, Jiang X, Xu Z. Curcumin inhibits proliferation of breast cancer cells through Nrf2-mediated down-regulation of Fen1 expression. J Steroid Biochem Mol Biol 2014:143:11-8.
16. Lee HR, Hwang KA, Park MA, Yi BR, Jeung EB, Choi KC. Treatment with bisphenol A and methoxychlor results in the growth of human breast cancer cells and alteration of the expression of cell cycle-related genes, cyclin D1 and p21, via an estrogen receptor-dependent signaling pathway. Int J Mol Med 2012;29:883-90.

17. Li X, Xie W, Xie C, Huang C, Zhu J, Liang Z, et al. Curcumin modulates miR-19/PTEN/AKT/p53 axis to suppress bisphenol A-induced MCF-7 breast cancer cell proliferation. Phytother Res 2014:28:1553-60.

18. Huang HC, Lin CL, Lin JK. 1,2,3,4,6-penta-O-galloyl- $\beta$-D-glucose, quercetin, curcumin and lycopene induce cell-cycle arrest in MDA-MB-231 and BT474 cells through downregulation of Skp2 protein. J Agric Food Chem 2011;59:6765-75.

19. Kim HY, Choi TW, Kim HJ, Kim SM, Park KR, Jang HJ, et al. A methylene chloride fraction of Saururus chinensis induces apoptosis through the activation of caspase- 3 in prostate and breast cancer cells. Phytomedicine 2011;18:567-74.

20. Chung BS, Shin MG. Dictionary of Korean folk medicine. Seoul, Young Lim Sa, 1990.

21. Bae HB, Li M, Son JK, Seo CS, Chung SH, Kim SJ, et al. Sauchinone, a lignan from Saururus chinensis, reduces tumor necrosis factor-alpha production through the inhibition of c-raf/MEK1/2/ ERK $1 / 2$ pathway activation. Int Immunopharmacol 2010;10: 1022-z8

22. Cagnol S, Chambard JC. ERK and cell death: mechanisms of ERK-induced cell death--apoptosis, autophagy and senescence. FEBS J 2010;277:2-21.

23. Escárcega RO, Fuentes-Alexandro S, García-Carrasco M, Gatica A, Zamora A. The transcription factor nuclear factor-kappa B and cancer. Clin Oncol (R Coll Radiol) 2007;19:154-61.

24. Hwang BY, Lee JH, Jung HS, Kim KS, Nam JB, Hong YS, et al. Sauchinone, a lignan from Saururus chinensis, suppresses iNOS expression through the inhibition of transactivation activity of RelA of NF-kappaB. Planta Med 2003;69:1096-101.

25. Kucuk O, Sarkar FH, Sakr W, Djuric Z, Pollak MN, Khachik F, et al. Phase II randomized clinical trial of lycopene supplementation before radical prostatectomy. Cancer Epidemiol Biomarkers Prev 2001:10:861-8.

26. Levy J, Bosin E, Feldman B, Giat Y, Miinster A, Danilenko M, et al. Lycopene is a more potent inhibitor of human cancer cell proliferation than either alpha-carotene or beta-carotene. Nutr Cancer 1995;24:257-66.

27. Koh MS, Hwang JS, Moon AR. Lycopene inhibits proliferation, invasion and migration of human breast cancer cells. Biomol Ther 2010;18:92-8.

28. Wang Y, Cui R, Xiao Y, Fang J, Xu Q. Effect of carotene and lycopene on the risk of prostate cancer: a systematic review and dose-response meta-analysis of observational studies. PLoS One 2015;10:e0137427.

29. Gann PH, Ma J, Giovannucci E, Willett W, Sacks FM, Hennekens $\mathrm{CH}$, et al. Lower prostate cancer risk in men with elevated plasma lycopene levels: results of a prospective analysis. Cancer Res 1999:59:1225-30.

30. Lin MC, Wang FY, Kuo YH, Tang FY. Cancer chemopreventive effects of lycopene: suppression of MMP-7 expression and cell invasion in human colon cancer cells. J Agric Food Chem 2011;59: 11304-18.

31. Lian F, Wang XD. Enzymatic metabolites of lycopene induce Nrf2-mediated expression of phase II detoxifying/antioxidant en- 
zymes in human bronchial epithelial cells. Int J Cancer 2008;123: 1262-8.

32. Ono M, Takeshima M, Nakano S. Mechanism of the anticancer effect of lycopene (tetraterpenoids). Enzymes 2015;37:139-66.

33. Kelkel M, Schumacher M, Dicato M, Diederich M. Antioxidant and anti-proliferative properties of lycopene. Free Radic Res 2011:45:925-40.

34. Petchsak P, Sripanidkulchai B. Momordica cochinchinensis aril extract induced apoptosis in human MCF-7 breast cancer cells. Asian Pac J Cancer Prev 2015; 16:5507-13.

35. Teodoro AJ, Oliveira FL, Martins NB, Maia Gde A, Martucci RB, Borojevic R. Effect of lycopene on cell viability and cell cycle progression in human cancer cell lines. Cancer Cell Int 2012;12:36.

36. Takeshima $M$, Ono $M$, Higuchi $T$, Chen $C$, Hara $T$, Nakano $S$. Anti-proliferative and apoptosis-inducing activity of lycopene against three subtypes of human breast cancer cell lines. Cancer Sci 2014;105:252-7.

37. Gloria NF, Soares N, Brand C, Oliveira FL, Borojevic R, Teodoro AJ. Lycopene and beta-carotene induce cell-cycle arrest and apoptosis in human breast cancer cell lines. Anticancer Res 2014:34:137786.

38. Nahum A, Hirsch K, Danilenko M, Watts CK, Prall OW, Levy J, et al. Lycopene inhibition of cell cycle progression in breast and endometrial cancer cells is associated with reduction in cyclin D levels and retention of p27(Kip1) in the cyclin E-cdk2 complexes. Oncogene 2001;20:3428-36.

39. Nahum A, Zeller L, Danilenko M, Prall OW, Watts CK, Sutherland RL, et al. Lycopene inhibition of IGF-induced cancer cell growth depends on the level of cyclin D1. Eur J Nutr 2006:45:275-82.

40. Shindo S, Hosokawa Y, Hosokawa I, Ozaki K, Matsuo T. Genipin inhibits MMP-1 and MMP-3 release from TNF-a-stimulated human periodontal ligament cells. Biochimie 2014;107 Pt B:391-5.

41. Koriyama Y, Chiba K, Yamazaki M, Suzuki H, Muramoto K, Kato S. Long-acting genipin derivative protects retinal ganglion cells from oxidative stress models in vitro and in vivo through the Nrf2/antioxidant response element signaling pathway. J Neurochem 2010;115:79-91.

42. Yang X, Yao J, Luo Y, Han Y, Wang Z, Du L. P38 MAP kinase mediates apoptosis after genipin treatment in non-small-cell lung cancer H1299 cells via a mitochondrial apoptotic cascade. J Pharmacol Sci 2013;121:272-81.

43. Pons DG, Nadal-Serrano M, Torrens-Mas M, Valle A, Oliver J, Roca P. UCP2 inhibition sensitizes breast cancer cells to therapeutic agents by increasing oxidative stress. Free Radic Biol Med 2015;86:67-77.

44. Ayyasamy V, Owens KM, Desouki MM, Liang P, Bakin A, Thangaraj $\mathrm{K}$, et al. Cellular model of Warburg effect identifies tumor promoting function of UCP2 in breast cancer and its suppression by genipin. PLoS One 2011;6:e24792.

45. Chen PH, Peng CY, Pai HC, Teng CM, Chen CC, Yang CR. Denbinobin suppresses breast cancer metastasis through the inhibition of Src-mediated signaling pathways. J Nutr Biochem 2011:22:732-40

46. Peiró G, Ortiz-Martínez F, Gallardo A, Pérez-Balaguer A, Sánchez-Payá J, Ponce JJ, et al. Src, a potential target for overcoming trastuzumab resistance in HER2-positive breast carcinoma. Br J Cancer 2014;111:689-95.

47. Liu HE, Chang AS, Teng CM, Chen CC, Tsai AC, Yang CR. Potent anti-inflammatory effects of denbinobin mediated by dual inhibition of expression of inducible no synthase and cyclo- oxygenase 2 . Shock 2011;35:191-7.

48. Tsai AC, Pan SL, Lai CY, Wang CY, Chen CC, Shen CC, et al. The inhibition of angiogenesis and tumor growth by denbinobin is associated with the blocking of insulin-like growth factor-1 receptor signaling. J Nutr Biochem 2011;22:625-33.

49. Magwere T. Escaping immune surveillance in cancer: is denbinobin the panacea? Br J Pharmacol 2009;157:1172-4.

50. Chen J, Hou R, Zhang X, Ye Y, Wang Y, Tian J. Calycosin suppresses breast cancer cell growth via $\mathrm{ER} \beta$-dependent regulation of IGF-1R, p38 MAPK and PI3K/Akt pathways. PLoS One 2014;9:e91245.

51. Huang G, Li M. The role of EphB4 and IGF-IR expression in breast cancer cells. Int J Clin Exp Pathol 2015;8:5997-6004

52. Kim S, Moon A. Capsaicin-induced apoptosis of H-ras-transformed human breast epithelial cells is Rac-dependent via ROS generation. Arch Pharm Res 2004:27:845-9.

53. Kang HJ, Soh Y, Kim MS, Lee EJ, Surh YJ, Kim HR, et al. Roles of JNK-1 and p38 in selective induction of apoptosis by capsaicin in ras-transformed human breast epithelial cells. Int J Cancer 2003; 103:475-82.

54. Wang J, Huang F, Bai Z, Chi B, Wu J, Chen X. Curcumol Inhibits Growth and Induces Apoptosis of Colorectal Cancer LoVo Cell Line via IGF-1R and p38 MAPK Pathway. Int J Mol Sci 2015; 16:19851-67.

55. Jung MY, Kang HJ, Moon A. Capsaicin-induced apoptosis in SK-Hep-1 hepatocarcinoma cells involves Bcl-2 downregulation and caspase-3 activation. Cancer Lett 2001;165:139-45.

56. Sarkar A, Bhattacharjee S, Mandal DP. Induction of apoptosis by eugenol and capsaicin in human gastric cancer AGS cells: elucidating the role of p53. Asian Pac J Cancer Prev 2015;16:6753-9.

57. Lin CH, Lu WC, Wang CW, Chan YC, Chen MK. Capsaicin induces cell cycle arrest and apoptosis in human $\mathrm{KB}$ cancer cells. BMC Complement Altern Med 2013;13:46.

58. Venier NA, Yamamoto T, Sugar LM, Adomat H, Fleshner NE, Klotz LH, et al. Capsaicin reduces the metastatic burden in the transgenic adenocarcinoma of the mouse prostate model. Prostate 2015:75:1300-11.

59. Min JK, Han KY, Kim EC, Kim YM, Lee SW, Kim OH, et al. Capsaicin inhibits in vitro and in vivo angiogenesis. Cancer Res 2004:64:644-51.

60. Chang HC, Chen ST, Chien SY, Kuo SJ, Tsai HT, Chen DR. Capsaicin may induce breast cancer cell death through apoptosis-inducing factor involving mitochondrial dysfunction. Hum Exp Toxicol 2011;30:1657-65.

61. Thoennissen NH, O'Kelly J, Lu D, Iwanski GB, La DT, Abbassi S, et al. Capsaicin causes cell-cycle arrest and apoptosis in ER-positive and -negative breast cancer cells by modulating the EGFR/HER-2 pathway. Oncogene 2010;29:285-96.

62. Shim Y, Song JM. Quantum dot nanoprobe-based high-content monitoring of notch pathway inhibition of breast cancer stem cell by capsaicin [Published online ahead of print September 15 . 2015]. Mol Cell Probes. doi: 10.1016/j.mcp.2015.09.004.

63. Scaltriti M, Baselga J. The epidermal growth factor receptor pathway: a model for targeted therapy. Clin Cancer Res 2006;12:526872.

64. Mendelsohn J, Baselga J. Status of epidermal growth factor receptor antagonists in the biology and treatment of cancer. J Clin Oncol 2003;21:2787-99.

65. Hwang MK, Bode AM, Byun S, Song NR, Lee HJ, Lee KW, et al. Cocarcinogenic effect of capsaicin involves activation of EGFR sig- 
naling but not TRPV1. Cancer Res 2010;70:6859-69.

66. Liu Z, Zhu P, Tao Y, Shen C, Wang S, Zhao L, et al. Cancer-promoting effect of capsaicin on DMBA/TPA-induced skin tumorigenesis by modulating inflammation, Erk and p38 in mice. Food Chem Toxicol 2015;81:1-8.

67. Li JS, Wang WJ, Sun Y, Zhang YH, Zheng L. Ursolic acid inhibits the development of nonalcoholic fatty liver disease by attenuating endoplasmic reticulum stress. Food Funct 2015;6:1643-51.

68. Kim ES, Moon A. Ursolic acid inhibits the invasive phenotype of SNU-484 human gastric cancer cells. Oncol Lett 2015;9:897-902.

69. Xiang L, Chi T, Tang Q, Yang X, Ou M, Chen X, et al. A pentacyclic triterpene natural product, ursolic acid and its prodrug US597 inhibit targets within cell adhesion pathway and prevent cancer metastasis. Oncotarget 2015:6:9295-312.

70. Zhang J, Wang W, Qian L, Zhang Q, Lai D, Qi C. Ursolic acid inhibits the proliferation of human ovarian cancer stem-like cells through epithelial-mesenchymal transition. Oncol Rep 2015;34: 2375-84.

71. Kim JH, Kim YH, Song GY, Kim DE, Jeong YJ, Liu KH, et al. Ursolic acid and its natural derivative corosolic acid suppress the proliferation of APC-mutated colon cancer cells through promotion of $\beta$-catenin degradation. Food Chem Toxicol 2014;67:87-95.

72. Saraswati S, Agrawal SS, Alhaider AA. Ursolic acid inhibits tumor angiogenesis and induces apoptosis through mitochondrial-dependent pathway in Ehrlich ascites carcinoma tumor. Chem Biol Interact 2013:206:153-65.

73. Yang X, Li Y, Jiang W, Ou M, Chen Y, Xu Y, et al. Synthesis and biological evaluation of novel ursolic acid derivatives as potential anticancer prodrugs [Published online ahead of print June 16, 2015]. Chem Biol Drug Des. doi: 10.1111/cbdd.12608.

74. Lamb R, Lehn S, Rogerson L, Clarke RB, Landberg G. Cell cycle regulators cyclin D1 and CDK4/6 have estrogen receptor-dependent divergent functions in breast cancer migration and stem cell-like activity. Cell Cycle 2013;12:2384-94.

75. Wang JS, Ren TN, Xi T. Ursolic acid induces apoptosis by suppressing the expression of FoxM1 in MCF-7 human breast cancer cells. Med Oncol 2012;29:10-5.

76. Yeh $\mathrm{CT}, \mathrm{Wu} \mathrm{CH}$, Yen GC. Ursolic acid, a naturally occurring triterpenoid, suppresses migration and invasion of human breast cancer cells by modulating c-Jun N-terminal kinase, Akt and mammalian target of rapamycin signaling. Mol Nutr Food Res 2010;54:1285-95.

77. Kim KH, Seo HS, Choi HS, Choi I, Shin YC, Ko SG. Induction of apoptotic cell death by ursolic acid through mitochondrial death pathway and extrinsic death receptor pathway in MDA-MB-231 cells. Arch Pharm Res 2011;34:1363-72.

78. Kassi E, Sourlingas TG, Spiliotaki M, Papoutsi Z, Pratsinis H, Aligiannis N, et al. Ursolic acid triggers apoptosis and Bcl-2 downregulation in MCF-7 breast cancer cells. Cancer Invest 2009;27: 723-33.

79. Bishayee A, Ahmed S, Brankov N, Perloff M. Triterpenoids as potential agents for the chemoprevention and therapy of breast cancer. Front Biosci (Landmark Ed) 2011;16:980-96.

80. Wang W, Zhang X, Qin JJ, Voruganti S, Nag SA, Wang MH, et al. Natural product ginsenoside 25-OCH3-PPD inhibits breast cancer growth and metastasis through down-regulating MDM2. PLoS One 2012;7:e41586.

81. Rayburn E, Zhang R, He J, Wang H. MDM2 and human malignancies: expression, clinical pathology, prognostic markers, and implications for chemotherapy. Curr Cancer Drug Targets 2005;5: 27-41.

82. Zhong Z, Dang Y, Yuan X, Guo W, Li Y, Tan W, et al. Furanodiene, a natural product, inhibits breast cancer growth both in vitro and in vivo. Cell Physiol Biochem 2012;30:778-90.

83. Zhong Z, Tan W, Chen X, Wang Y. Furanodiene, a natural small molecule suppresses metastatic breast cancer cell migration and invasion in vitro. Eur J Pharmacol 2014;737:1-10.

84. Wang W, Chen B, Zou R, Tu X, Tan S, Lu H, et al. Codonolactone, a sesquiterpene lactone isolated from Chloranthus henryi Hemsl, inhibits breast cancer cell invasion, migration and metastasis by downregulating the transcriptional activity of Runx2. Int J Oncol 2014:45:1891-900.

85. Wang $C D$, Yuan $C F, B u$ YQ, Wu XM, Wan JY, Zhang L, et al. Fangchinoline inhibits cell proliferation via Akt/GSK-3beta/ cyclin D1 signaling and induces apoptosis in MDA-MB-231 breast cancer cells. Asian Pac J Cancer Prev 2014;15:769-73.

86. Jin H, Lee WS, Eun SY, Jung JH, Park HS, Kim G, et al. Morin, a flavonoid from Moraceae, suppresses growth and invasion of the highly metastatic breast cancer cell line MDA-MB-231 partly through suppression of the Akt pathway. Int J Oncol 2014:45: 1629-37.

87. Yan G, Lanza-Jacoby S, Wang C. Nexrutine inhibits survival and induces G1 cell cycle arrest, which is associated with apoptosis or autophagy depending on the breast cancer cell line. Nutr Cancer 2014:66:506-16.

88. Wu C, Sun Z, Ye Y, Han X, Song X, Liu S. Psoralen inhibits bone metastasis of breast cancer in mice. Fitoterapia 2013;91:205-10.

89. Koay DC, Zerillo C, Narayan M, Harris LN, DiGiovanna MP. Anti-tumor effects of retinoids combined with trastuzumab or tamoxifen in breast cancer cells: induction of apoptosis by retinoid/trastuzumab combinations. Breast Cancer Res 2010;12:R62.

90. Simeone AM, Tari AM. How retinoids regulate breast cancer cell proliferation and apoptosis. Cell Mol Life Sci 2004;61:1475-84.

91. Mense SM, Hei TK, Ganju RK, Bhat HK. Phytoestrogens and breast cancer prevention: possible mechanisms of action. Environ Health Perspect 2008;116:426-33.

92. Sirotkin AV, Harrath AH. Phytoestrogens and their effects. Eur J Pharmacol 2014;741:230-6.

93. Hsieh CJ, Kuo PL, Hsu YC, Huang YF, Tsai EM, Hsu YL. Arctigenin, a dietary phytoestrogen, induces apoptosis of estrogen receptor-negative breast cancer cells through the ROS/p38 MAPK pathway and epigenetic regulation. Free Radic Biol Med 2014;67: 159-70.

94. Khan SI, Zhao J, Khan IA, Walker LA, Dasmahapatra AK. Potential utility of natural products as regulators of breast cancer-associated aromatase promoters. Reprod Biol Endocrinol 2011;9:91.

95. Lu R, Serrero G. Resveratrol, a natural product derived from grape, exhibits antiestrogenic activity and inhibits the growth of human breast cancer cells. J Cell Physiol 1999:179:297-304.

96. Wang Z, Wang N, Han S, Wang D, Mo S, Yu L, et al. Dietary compound isoliquiritigenin inhibits breast cancer neoangiogenesis via VEGF/VEGFR-2 signaling pathway. PLoS One 2013;8:e68566.

97. Moon D, McCormack D, McDonald D, McFadden D. Pterostilbene induces mitochondrially derived apoptosis in breast cancer cells in vitro. J Surg Res 2013;180:208-15.

98. Noori S, Hassan ZM. Tehranolide inhibits proliferation of MCF-7 human breast cancer cells by inducing G0/G1 arrest and apoptosis. Free Radic Biol Med 2012;52:1987-99. 